\title{
Crocin Protects Malathion-induced Parkinson-like Disease by Inhibiting Apoptosis and a-synuclein Accumulation in Rats' Striatum
}

Leila Mohammadzadeh

Mashhad University of Medical Sciences

Mahboobeh Ghasemzadeh Rahbardar

Mashhad University of Medical Sciences

Bibi Marjan Razavi

Mashhad University of Medical Sciences

Hossein Hosseinzadeh ( $\nabla$ hosseinzadehh@mums.ac.ir)

mashhad university of medical sciences https://orcid.org/0000-0002-3483-851X

\section{Research Article}

Keywords: Crocin, malathion, apoptosis, neurotoxicity, Parkinson's disease

Posted Date: November 16th, 2021

DOI: https://doi.org/10.21203/rs.3.rs-1028580/v1

License: (c) (i) This work is licensed under a Creative Commons Attribution 4.0 International License.

Read Full License 


\section{Abstract}

\section{Background}

Long-term exposure to organophosphates might result in neurodegenerative diseases, comprising Parkinson's disease. Malathion is an organophosphate pesticide with high neurotoxicity. Oxidative stress, apoptosis, and a-synuclein accumulation are important underlying mechanisms in Parkinson's disease. According to studies, crocin, an active constituent of saffron, has anti-apoptotic, anti-inflammatory, and anti-oxidant properties. Thus, the effect of crocin on malathion-induced Parkinson-like disease in rats was investigated in this study.

Materials and methods

6 groups of male Wistar rats were used: 1 . Control (normal saline), 2. Malathion ( $100 \mathrm{mg} / \mathrm{kg} / \mathrm{day}, \mathrm{i} . \mathrm{p}), 3$. Crocin (10 mg/kg/day, i.p) + malathion, 4. Levodopa (10 mg/kg/day, i.p) +malathion, 5. Crocin (40 $\mathrm{mg} / \mathrm{kg} /$ day, i.p), and 6. Polyethylene glycol (PEG) (vehicle of levodopa) groups. The drugs were administered for 28 days. The amounts of Bcl-2, Bax, caspases 3, 8, 9 proteins in the striatum were measured by western blotting. Also, the amounts of protein and mRNA level of the a-synuclein in striatum tissue were measured by western blotting and RT-qPCR methods.

Results

Malathion induced apoptosis by increasing the amount of $\mathrm{Bax} / \mathrm{Bcl} 2$ ratio, caspase 3 and 9 proteins in rat striatum tissue. It also increased the protein and mRNA level of a-synuclein in striatal tissue. Coadministration of crocin or levodopa with malathion inhibited the toxic effects of malathion on striatal tissue.

\section{Conclusion}

Crocin ameliorates the neurotoxic effect of malathion by its anti-apoptotic activity and regulating the expression of proteins involved in Parkinson's disease pathogenesis. As a result, crocin has the potential to be used as a treatment for malathion-induced neurotoxicity.

\section{Introduction}

Parkinson's disease is the second most common chronic neurological disease. The loss of dopaminergic neurons in the substantia nigra pars compacta over time defines this condition (Emamzadeh and Surguchov 2018). Motor (hypokinesia, bradykinesia, tremor, swallowing, and speech disorder) and nonmotor (sleep and cognitive disorder) symptoms are common in Parkinson's disease (Connolly and Lang 2014). Oxidative stress, inflammatory factors, aquaporin 4, a-synuclein accumulation, and apoptotic pathways appear to have an impact on the pathogenesis of Parkinson's disease (Anglade et al. 1997; Emamzadeh and Surguchov 2018; Hughes et al. 1992; Jenner 2003; Zucca et al. 2017). According to evidence, genetics and environmental factors can both play a part in the disease progression (Warner 
and Schapira 2003). Pesticides, herbicides, and heavy metals are some of the most well-known environmental pollutants inducing Parkinson's disease (Agim and Cannon, 2015).

Malathion (0,0'-dimethyl dithiophosphate of diethyl mercaptosuccinate) is an organophosphate insecticide that binds to cholinesterase enzymes in animals such as acetylcholinesterase (AChE) and butyrylcholinesterase (BChE). Malathion is a pesticide used in agriculture including beans, lettuce, broccoli, cherries, strawberries, and peaches and all over the world, as well as in homes for mosquito control (Venkatesan et al. 2017). In the rat brain, increased caspase-3 activity and the beginning of toxic consequences are the results of malathion toxicity (Varol et al. 2015). Furthermore, after exposure to malathion, Gibco ${ }^{\circledR}$ Human Astrocytes (GHA cells) showed cell cycle arrest, reactive oxygen species (ROS) formation, a weakening of cellular antioxidant defenses, and apoptosis (Bcl-2, Bax, and cleaved caspase9/caspase-3) (Shieh et al. 2019).

Parkinson's disease has a multifactorial etiology, and there is no single medication that can stop the disease from progressing. The only treatments for motor problems that are currently available are symptomatic. For example, levodopa is a common medicine that is also the most effective treatment for Parkinson's disease (Jankovic and Stacy 2007). However, it has been documented that consumption of levodopa results in various complications (Thanvi and Lo 2004; Toth et al. 2008).

Today, the beneficial effects of various medicinal plants including Curcuma longa (Ma and Guo 2017), Gingko Biloba (Yu et al. 2020), Rosmarinus officinalis L. (Rahbardar and Hosseinzadeh 2020a, b), and Camellia sinensis (Malar et al. 2020) have been demonstrated in the treatment of Parkinson's disease and other age-related disorders (Amro et al. 2018; Srivastav et al. 2017).

Crocus sativus belongs to the Iridaceae family of plants. It's known as saffron, and its main monomer component, crocin, has been used to treat several ailments for decades (Hosseinzadeh et al. 2004; Razavi et al. 2021), memory deficits (Shahidani et al. 2019), Parkinson's disease (Mohammadzadeh et al. 2018; Tang et al. 2020), anxiety (Hosseinzadeh and Noraei 2009), and other neurodegenerative diseases (Khalatbari-Mohseni et al. 2019; Shaterzadeh-Yazdi et al. 2018). The therapeutic effects of crocin are due to its antioxidant (Hosseinzadeh et al. 2009; Margaritis et al. 2020), antiinflammatory (Hassani et al. 2014; Zeinali et al. 2019), anti-apoptotic (Mohammadzadeh et al. 2020), antitumor (Rastgoo et al. 2013), and neuroprotective (Hosseinzadeh et al. 2012; Mehri et al. 2015; Mehri et al. 2012) properties. Crocin has also been shown to lower the amount of a-synuclein in rats with rotenone-induced Parkinson's disease (Salama et al. 2020).

As a result, in our previous research, the protective effect of crocin $(10,20,40 \mathrm{mg} / \mathrm{kg}, 28$ days, i.p.) against malathion-induced Parkinson-like behavior, oxidative stress, and inflammation was examined in rat striatum. In this study, our team evaluated the effect of 28 days of intraperitoneal administration of crocin $(10 \mathrm{mg} / \mathrm{kg} /$ day) on the malathion-induced Parkinson-like disease on rats by assessing the levels of Bcl-2, Bax, caspases 3, 8, 9, and the amounts of protein and mRNA level of a-synuclein in striatum tissue by Western blotting and RT-qPCR methods. 


\section{Materials And Methods}

\section{Animals}

Male Wistar rats weighing 200 to $250 \mathrm{~g}$ were acquired from the animal department of the School of Pharmacy, Mashhad, Iran. Animals were kept at 22 to $25^{\circ} \mathrm{C}$ and 12 hours in light and 12 hours in darkness. There were no restrictions on water and food consumption. All animal studies were carried out in accordance with the norms of the Ethics Committee of Mashhad University of Medical Sciences (No: 931316, 15.03.2017).

\section{Chemicals}

For the current research, levodopa and malathion (purity 96\%) were obtained from Ramopharmin, Iran, and Ariashimi factory, Zahedan, Iran, respectively. Xylazine and ketamine were attained from Alfasan Pharmaceutical Co., Woerden, Netherlands. Stigmas of C. sativus L. were bought from Novin Saffron and were evaluated according to the ISO/TS 3632-2. The isolation and purification of crocin were performed as described previously (Hadizadeh et al. 2010).

\section{Study Protocol}

Male Wistar rats were randomly assigned to one of seven groups $(n=4)$ :

Group 1: Normal saline was injected intraperitoneally to the rats of this group.

Group 2: Malathion (100 mg/kg/day, i.p.) (Delgado et al. 2006).

Group 3: Malathion (100 mg/kg/day, i.p.) with crocin (10 mg/kg/day, i.p.) (Dorri et al. 2015).

Group 4: Crocin (40 mg/kg/day, i.p.)

Group 5: Malathion (100 mg/kg/day, i.p.) with levodopa (10 mg/kg, i.p.) (Sandhu and Rana 2013).

Group 6: Polyethylene glycol (PEG) group (vehicle of levodopa).

For 28 days, agents were injected. The weight of rats was recorded before the study and any weight change was calculated in the dosage calculation.

\section{Western blot analysis}

Striatum tissue was homogenized in a lysis buffer containing $2 \mathrm{mM}$ Ethylenediaminetetraacetic acid (EDTA), $50 \mathrm{mM}$ Tris- $\mathrm{HCl}$ (pH: 7.4), 10mM NaF, 2mM ethylene glycol tetraacetic acid (EGTA), $10 \mathrm{mM} \beta-$ glycerophosphate, $1 \mathrm{mM}$ sodium orthovanadate (Na3V04), $0.2 \% \mathrm{~W} / \mathrm{V}$ sodium deoxycholate, $1 \mathrm{mM}$ phenylmethylsulfonyl fluoride, as well as complete protease inhibitor cocktail (Sigma Aldrich, USA). The protein concentration of various samples was determined using the Bradford assay kit (Bio-Rad, USA). 
The samples were then combined with 2X Sodium Dodecyl Sulfate (SDS) blue buffer, boiled for 5-7 minutes, aliquoted to smaller sample quantities, and stored at $-80^{\circ} \mathrm{C}$.

To determine the amount of various proteins, samples were electrophoresed on an SDS polyacrylamide gel and transferred to a polyvinylidene difluoride (PVDF) membrane (Bio-Rad, USA). On a rocker, the blots were blocked for 2 hours at room temperature with 5\% skimmed milk in Tris-buffered saline tween 20 (TBST). The blots were then washed three times with TBST before being incubated for two hours at room temperature with rabbit polyclonal antiserum against Bax (Cell Signaling \#2772, 1:1000), rabbit monoclonal antiserum against Bcl-2 (Cell Signaling \#2870, 1: 1000), and rabbit polyclonal antiserum against Bcl-2 (Cell Signaling \#2870, 1: 1000), rabbit monoclonal anti-serum against caspase-3 (Cell Signaling \#9665, 1: 1000), rabbit monoclonal anti-serum against caspase-8 (Abcam, \#32397, EJ), and rabbit monoclonal anti-serum against caspase-9 (Abcam, \#32539, E23). Blots were incubated for 1.5 hours at room temperature with anti-rabbit IgG labeled with horseradish peroxidase (Cell Signaling, $\# 7074,1: 3000$ ) or anti-mouse IgG labeled with horseradish peroxidase (Cell Signaling, \#7076, 1:3000) after three washes with TBST. Enhanced chemiluminescence was used to detect the peroxidase-coated bands (Pierce, USA). Alliance $4.7 \mathrm{Gel}$ doc (UK) was used to assess band optical densities, and UVITEC software was used to perform densitometric analysis on protein bands (UK). The protein levels were compared to the equivalent bands of $\beta$-actin, which served as a control protein.

\section{RNA isolation and RT qPCR}

Tripure Isolation Reagent (Roche, Cat \#11667157001) was used to extract total RNAs from different samples, as directed by the manufacturer. Nanodrop (NanoDropTM 2000, USA) was used to assess the quality (260/280 and $260 / 230$ ratios) and amount of extracted RNAs, and samples were stored at $-80^{\circ} \mathrm{C}$ until use. Transcript levels were determined using the Express one-step SYBR Green ERTM kit (Invitrogen, Cat \#11780-200) and the Phase one thermal cycler (ABI). BioSoft's beacon modeling program was used to generate protein and -actin primers (Table 1 ). The uniformity of primers and products was assessed using melting curve analysis. Target gene expression was normalized in comparison to $\beta$-actin. The $\triangle \triangle C T$ method was used to compute the fold increase of genes compared to the control group (Razavi et al. 2013).

\section{Data analysis and statistical calculations}

Prism software program 6 was used for statistical calculations. One-way ANOVA and the Tukey-Kramer post-test were used to compare different groups in different experiments. The results were expressed as mean \pm SEM, with $p<0.05$ considered statistically significant.

\section{Results}

The effect of malathion and crocin on the amount of Bax and Bcl-2 proteins 
Comparing with the control group, malathion $(100 \mathrm{mg} / \mathrm{kg})$ caused a substantial increase in the ratio of $\mathrm{Bax} / \mathrm{Bcl}-2$ proteins in rat striatum tissue after 4 weeks $(\mathrm{p}<0.05)$. In comparison to the malathion group, crocin $10 \mathrm{mg} / \mathrm{kg}(\mathrm{p}<0.001)$ and levodopa $10 \mathrm{mg} / \mathrm{kg}(\mathrm{p}<0.01)$ administration with malathion resulted in a significant decrease in the ratio of $\mathrm{Bax} / \mathrm{Bcl}-2$ proteins in rat striatum tissue.

The effect of administration of crocin $40 \mathrm{mg} / \mathrm{kg}$ alone or PEG on the Bax/Bcl-2 protein ratio was similar to the control group (Fig. 1).

\section{The effect of malathion and crocin on the amount of cleaved caspase-3 protein}

Comparing with the control group, malathion $(100 \mathrm{mg} / \mathrm{kg})$ caused a substantial increase in cleaved caspase-3 protein concentration in rat striatum tissue after four weeks $(p<0.001)$. In comparison to the malathion group, crocin $(10 \mathrm{mg} / \mathrm{kg})$ or levodopa $(10 \mathrm{mg} / \mathrm{kg})$ administration with malathion significantly reduced the amount of cleaved caspase-3 protein in rat striatum tissue $(p<0.001)$.

Crocin $40 \mathrm{mg} / \mathrm{kg}$ alone or PEG had a similar effect on the amount of cleaved caspase-3 protein as the control group (Fig. 2).

\section{The effect of malathion and crocin on the amount of caspase- 8 protein}

Comparing with the control group, the effect of malathion $(100 \mathrm{mg} / \mathrm{kg})$ on cleaved caspase- 8 and procaspase-8 protein levels in rat striatum tissue after four weeks was not significant.

Crocin $40 \mathrm{mg} / \mathrm{kg}$ alone or PEG had a similar effect on the amount of cleaved and pro-caspase 8 protein as the control group (Fig. 3).

\section{The effect of malathion and crocin on the amount of cleaved caspase-9 protein}

Comparing with the control group, malathion $(100 \mathrm{mg} / \mathrm{kg})$ caused a substantial increase in cleaved caspase-9 protein concentration in rat striatum tissue after four weeks $(p<0.05)$.

When crocin $10 \mathrm{mg} / \mathrm{kg}(\mathrm{p}<0.01)$ or levodopa $10 \mathrm{mg} / \mathrm{kg}(\mathrm{p}<0.001)$ was administered with malathion, the amount of cleaved caspase-9 protein in rat striatum tissue was much lower than when malathion was given alone (Fig. 4).

On the amount of cleaved caspase-9 protein, $40 \mathrm{mg} / \mathrm{kg}$ crocin alone or PEG had a similar effect as the control group.

\section{The effect of malathion and crocin on the a-synuclein protein level}

Comparing with the control group, malathion $(100 \mathrm{mg} / \mathrm{kg})$ induced a substantial increase in the amount of a-synuclein protein in rat striatum tissue after four weeks $(p<0.05)$ (Fig. 5).

In comparison to the malathion group, the treatment of crocin $10 \mathrm{mg} / \mathrm{kg}(\mathrm{p}<0.001)$ or levodopa $10 \mathrm{mg} / \mathrm{kg}$ $(p<0.01)$ with malathion resulted in a significant decrease in the amount of $a$-synuclein protein in striatum 
tissue.

On the amount of a-synuclein protein, $40 \mathrm{mg} / \mathrm{kg}$ crocin alone or PEG had a similar effect as the control group.

\section{The effect of malathion and crocin on the a-synuclein mRNA level}

Comparing with the control group, malathion $(100 \mathrm{mg} / \mathrm{kg})$ caused a substantial rise in a-synuclein mRNA levels in rat striatum tissue after four weeks $(p<0.001)$. In comparison to the malathion group, the administration of crocin (10 mg/ $\mathrm{kg})$ or levodopa $(10 \mathrm{mg} / \mathrm{kg})$ with malathion reduced the level of asynuclein mRNA in rat striatum tissue $(p<0.001)$.

Crocin $40 \mathrm{mg} / \mathrm{kg}$ alone or PEG had a similar effect on the expression of the a-synuclein gene as the control group (Fig. 6).

Table 1.Sequences of different primers used for RT qPCR reactions.

\begin{tabular}{|lll|}
\hline Gene & Primer & Sequence \\
\hline a-Synuclein & Forward & GCCTAAGAATGTCGTTGT \\
& Reversed & TGGAACTGAGCACTTGTA \\
\hline
\end{tabular}

\section{Discussion}

Our goal in this study was to find out if crocin may protect rats from developing Parkinson-like disease due to increased apoptotic factors and a-synuclein accumulation caused by malathion. The data disclosed that administration of crocin $(10 \mathrm{mg} / \mathrm{kg})$ and malathion $(100 \mathrm{mg} / \mathrm{kg})$ to animals for 28 days reduced the $\mathrm{Bax} / \mathrm{Bcl}-2$ ratio and the amount of cleaved caspase-3 and 9 . It also attenuated both protein and mRNA levels of a-synuclein. Furthermore, when levodopa (10 mg/kg) was administered concurrently with malathion, as a reference drug (Sandhu and Rana, 2013), the amount of apoptotic factors (Bax/Bcl2 ratio, cleaved caspase-3 and 9), as well as protein and mRNA levels of a-synuclein, were reduced.

In our previous study, our team investigated the neuroprotective effect of crocin in contradiction of the malathion-induced neurochemical changes and motor deficits in rats by performing behavioral tests (open field, rotarod, and catalepsy), assessing AChE level in serum, the levels of malondialdehyde (MDA), reduced glutathione (GSH), tumor necrosis factor-alpha (TNF-a), and Interleukin 6 (IL-6) in the striatum. The obtained data illustrated that sub-chronic malathion exposure resulted in Parkinson-like disease. Crocin protected against malathion-induced Parkinson's disease by lowering lipid peroxidation, ameliorating motor deficits, and revealing antioxidant and anti-inflammatory properties (Mohammadzadeh et al. 2018). Therefore, our team decided to assess other mechanisms to unveil the therapeutic potential of crocin against Parkinson-like disease. 
Apoptosis has been discovered as a significant factor in the development of several brain diseases (Singh et al. 2019). Apoptosis is triggered by a multitude of executioner and initiator caspases, and it can happen in either intrinsic or extrinsic pathways. The intrinsic pathway, known as the mitochondria-mediated pathway, is mediated by activating caspase-9, the initiator caspase. Activation of initiator caspase-8, on the other hand, promotes the cell death receptor-mediated extrinsic apoptotic pathway. Both initiator caspases culminate on a common executioner caspase pathway including caspase-3. The executioner caspases are activated, resulting in morphological characteristics associated with apoptosis, for instance, DNA fragmentation and cleavage. Bax and other pro-apoptotic factors have been linked to neuronal cell death in Parkinson's disease (Erekat 2018). Members of the Bcl-2 family influence apoptosis in numerous systems, with the Bax/bcl-2 ratio acting as a rheostat to determine cell apoptosis susceptibility (Korsmeyer 1999). The results of the present study illustrated that malathion induces apoptosis in the striatum by increasing Bax/Bcl-2 ratio. The amount of cleaved caspase- 3 was also measured to verify the induction of apoptosis by malathion. Besides, caspase 8 and 9 protein levels were measured to determine the pathway of malathion-induced apoptosis. In this part of the study, malathion did not change the amount of caspase-8 and caused apoptosis by increasing cleaved caspase-9 (via the intrinsic pathway) and cleaved caspase-3 in the striatum.

Crocin administration along with malathion reduced the Bax/Bcl-2 ratio, according to our findings. Crocin also inhibited malathion-induced caspases 3 and 9 in the striatum. The effect of other pesticides on apoptosis in the nervous system has been demonstrated in different in vitro and in vitro models. For example, a study showed that chlorpyrifos ( $100 \mu \mathrm{mol}, 24$ hours) induced apoptosis in the dopaminergic neuronal components of PC12 cells by activation of caspases 3 and 9 (Lee et al. 2012). Another study reported that intraperitoneal injection of a single dose of paraquat $(10.96 \mathrm{mg} / \mathrm{kg})$ triggered apoptosis in rat hippocampus and striatum (Wu et al. 2013).

In an earlier investigation, subacute administration of malathion $(2.5,5,10 \mathrm{mg} / \mathrm{kg}, 28$ days) to rats increased caspase-3 levels in brain tissue cells (Varol et al. 2015). In a study carried out on lymphocytes taken from rats, it was shown that malathion exposure at 0.1 and 0.25 of $\mathrm{LC}_{50}$ concentration for $2,4,8$, and 12 hours increased the levels of caspase 3 and 9 (Ojha and Gupta 2017).

Moreover, the anti-apoptotic property of crocin has previously been demonstrated in several studies. For instance, the oral administration of crocin ( $40 \mathrm{mg} / \mathrm{kg}, 10$ days) inhibited apoptosis in the brain tissue. Apoptosis was triggered in rats by cerebral ischemia, but receiving crocin decreased the amount of caspase-3 (Oruc et al. 2016). Another research stated that administering crocin intraperitoneally $(25,50$ $\mathrm{mg} / \mathrm{kg}$, 4 weeks) decreased the amount of caspase 3 and 9, as well as Bax in heart tissue in diazinoninduced cardiac toxicity in rats (Razavi et al. 2016).

Other molecular mechanisms involved in the development of Parkinson's disease following exposure to pesticides include the formation of protein clusters called Lewy bodies, which have been specifically attributed to the death of neurons in association with Parkinson's disease. a-synuclein is a protein that is found in high concentrations in Lewy bodies and its amount increases in Parkinson's disease (Thakur 
and Nehru 2014). Studies have shown that numerous pesticides, such as dieldrin, rotenone, and paraquat can stimulate the production of a-synuclein fibrils, a mechanism that has been suggested as the molecular basis for Parkinson's disease (Uversky et al. 2001). It has also been suggested that subcutaneous injection of low doses of rotenone increases the a-synuclein amount in nigrostriatal neurons (Sherer et al. 2003). Furthermore, it has been shown that paraquat significantly accelerated the production of fibril a-synuclein in vitro in a dose-dependent manner. Mice exposure to paraquat also increases the amount of this substance in the brain. The results of this study indicate the increased expression of a-synuclein, as a result of exposure to the toxic agent and also direct interaction between protein and environmental factors, as potential mechanisms in neurodegenerative disorders including Parkinson's disease (Manning-Boğ et al. 2003).

The increased amount of a-synuclein expression impairs mitochondrial function. In other words, impaired mitochondrial activity is the result of increased a-synuclein content and expression. Many reports illustrated that an increased amount of a-synuclein expression causes complex 1 damage in mitochondria (Chu et al. 2014).

The results of the current research showed that malathion increased the level of a-synuclein and its mRNA, while crocin suppressed the increased malathion-induced a-synuclein levels in the striatum.

The obtained data also indicated that levodopa ( $10 \mathrm{mg} / \mathrm{kg}, 28$ days, i.p.) inhibited apoptotic pathways and the aggregation of a-synuclein induced by malathion in rats' striatum. In line with our study, previous research has shown that levodopa administration can improve a-synuclein DNA methylation in Parkinson's disease patients (Schmitt et al. 2015) and ameliorate the symptoms of this disorder (Mohammadzadeh et al. 2018).

\section{Conclusion}

The current study concludes that malathion administration can cause Parkinson-like disease in rats by activating the apoptotic pathway and increasing a-synuclein accumulation in the striatum. Crocin can prevent malathion-induced changes in rats' brains. As a result, more clinical trials are needed to confirm the protective effect of crocin against malathion-induced Parkinson-like disease and to develop a new strategy for treating chronic malathion poisoning.

\section{Declarations}

\section{Data availability statements}

The data that support the findings of this study are available from the corresponding author upon reasonable request.

\section{ETHICAL STATEMENT:}




\section{Ethics approval and consent to participate}

All animal studies were carried out in accordance with the norms of the Ethics Committee of Mashhad University of Medical Sciences (No: 931316, 15.03.2017).

\section{Consent for publication}

All authors have agreed to the contents and approved the final version for publication.

\section{Availability of data and materials}

The data that support the findings of this study are available from the corresponding author upon reasonable request.

\section{Competing interests}

The authors declare that they have no conflicts of interest.

\section{Funding}

This research was supported by the Vice-Chancellor of Research, Mashhad University of Medical Sciences (No:931316).

\section{Authors' contributions}

$\mathrm{HH}$ and BMR were supervisors, designed the work, revised it critically for important intellectual content, and approved the version to be published. LM did the experiment and MGR wrote the manuscript.

\section{Acknowledgements}

This work was supported by the Pharmaceutical Research Center and the Vice-Chancellor of Research, Mashhad University of Medical Sciences.

\section{References}

Agim ZS, Cannon JR (2015) Dietary factors in the etiology of Parkinson's disease. Biomed Res Int 2015:672838.

Amro M, Teoh S, Norzana A, Srijit D (2018) The potential role of herbal products in the treatment of Parkinson's disease. Clin Ter 169:e23-e33.

Anglade P, Vyas S, Javoy-Agid F, Herrero M, Michel P, Marquez J, Mouatt-Prigent A, Ruberg M, Hirsch E, Agid $Y$ (1997) Apoptosis and autophagy in nigral neurons of patients with Parkinson's disease. Histol Histopathol 12:24-31. 
Chu Y, Goldman JG, Kelly L, He Y, Waliczek T, Kordower JH (2014) Abnormal alpha-synuclein reduces nigral voltage-dependent anion channel 1 in sporadic and experimental Parkinson's disease. Neurobiol Dis 69:1-14.

Connolly BS, Lang AE (2014) Pharmacological treatment of Parkinson disease: a review. Jama 311:16701683.

Delgado EH, Streck EL, Quevedo JL, Dal-Pizzol F (2006) Mitochondrial respiratory dysfunction and oxidative stress after chronic malathion exposure. Neurochem Res 31:1021-1025.

Dorri SA, Hosseinzadeh H, Abnous K, Hasani FV, Robati RY, Razavi BM (2015) Involvement of brainderived neurotrophic factor (BDNF) on malathion induced depressive-like behavior in subacute exposure and protective effects of crocin. Iran J Basic Med Sci 18:958-966.

Emamzadeh FN, Surguchov A (2018) Parkinson's disease: biomarkers, treatment, and risk factors. Front Neurosci 12:612.

Erekat NS (2018) Apoptosis and its role in Parkinson's disease. Stoker TB, JC G, editors: Codon Publications. 65-82 p.

Hadizadeh F, Mohajeri S, Seifi M (2010) Extraction and purification of crocin from saffron stigmas employing a simple and efficient crystallization method. Pak J Biol Sci 13:691-698.

Hassani FV, Naseri V, Razavi BM, Mehri S, Abnous K, Hosseinzadeh H (2014) Antidepressant effects of crocin and its effects on transcript and protein levels of CREB, BDNF, and VGF in rat hippocampus. DARU J Pharm Sci 22:1-9.

Hosseinzadeh H, Karimi G, Niapoor M (2004) Antidepressant effects of Crocus sativus stigma extracts and its constituents, crocin and safranal, in mice. J Medicinal Plants 3:48-58.

Hosseinzadeh H, Noraei NB (2009) Anxiolytic and hypnotic effect of Crocus sativus aqueous extract and its constituents, crocin and safranal, in mice. Phytother Research 23:768-774.

Hosseinzadeh H, Sadeghnia HR, Ghaeni FA, Motamedshariaty VS, Mohajeri SA (2012) Effects of saffron (Crocus sativus L.) and its active constituent, crocin, on recognition and spatial memory after chronic cerebral hypoperfusion in rats. Phytother Res 26:381-386.

Hosseinzadeh H, Shamsaie F, Mehri S (2009) Antioxidant activity of aqueous and ethanolic extracts of Crocus sativus L. stigma and its bioactive constituents, crocin and safranal. Pharmacogn Mag 5:419424.

Hughes AJ, Daniel SE, Kilford L, Lees AJ (1992) Accuracy of clinical diagnosis of idiopathic Parkinson's disease: a clinico-pathological study of 100 cases. J Neurol Neurosurg Psychiatry 55:181-184. 
Jankovic J, Stacy M (2007) Medical management of levodopa-associated motor complications in patients with Parkinson's disease. CNS drugs 21:677-692.

Jenner P (2003) Oxidative stress in Parkinson's disease. Ann Neurol 53:S26-S38.

Khalatbari-Mohseni A, Banafshe HR, Mirhosseini N, Asemi Z, Ghaderi A, Omidi A (2019) The effects of crocin on psychological parameters in patients under methadone maintenance treatment: a randomized clinical trial. Subst Abuse Treat Prev Policy 14:1-8.

Korsmeyer SJ (1999) BCL-2 gene family and the regulation of programmed cell death. Cancer Res 59:1693s-1700s.

Lee JE, Park JH, Shin IC, Koh HC (2012) Reactive oxygen species regulated mitochondria-mediated apoptosis in PC12 cells exposed to chlorpyrifos. Toxicol Appl Pharmacol 263:148-162.

Ma XW, Guo RY (2017) Dose-dependent effect of Curcuma longa for the treatment of Parkinson's disease. Exp Ther Med 13:1799-1805.

Malar DS, Prasanth MI, Brimson JM, Sharika R, Sivamaruthi BS, Chaiyasut C, Tencomnao T (2020) Neuroprotective properties of green tea (Camellia sinensis) in Parkinson's disease: a review. Molecules 25:3926.

Manning-Boğ AB, McCormack AL, Purisai MG, Bolin LM, Di Monte DA (2003) a-Synuclein overexpression protects against paraquat-induced neurodegeneration. J Neurosci 23:3095-3099.

Margaritis I, Angelopoulou K, Lavrentiadou S, Mavrovouniotis IC, Tsantarliotou M, Taitzoglou I, Theodoridis A, Veskoukis A, Kerasioti E, Kouretas D (2020) Effect of crocin on antioxidant gene expression, fibrinolytic parameters, redox status and blood biochemistry in nicotinamide-streptozotocininduced diabetic rats. J Biol Res 27:1-15.

Mehri S, Abnous K, Khooei A, Mousavi SH, Shariaty VM, Hosseinzadeh H (2015) Crocin reduced acrylamide-induced neurotoxicity in Wistar rat through inhibition of oxidative stress. Iran J Basic Med Sci 18:902-908.

Mehri S, Abnous K, Mousavi SH, Shariaty VM, Hosseinzadeh H (2012) Neuroprotective effect of crocin on acrylamide-induced cytotoxicity in PC12 cells. Cell Mol Neurobiol 32:227-235.

Mohammadzadeh L, Abnous K, Razavi BM, Hosseinzadeh H (2020) Crocin-protected malathion-induced spatial memory deficits by inhibiting TAU protein hyperphosphorylation and antiapoptotic effects. Nutr Neurosci 23:221-236.

Mohammadzadeh L, Hosseinzadeh H, Abnous K, Razavi BM (2018) Neuroprotective potential of crocin against malathion-induced motor deficit and neurochemical alterations in rats. Environ Sci Pollut Res 25:4904-4914. 
Ojha A, Gupta Y (2017) Study of commonly used organophosphate pesticides that induced oxidative stress and apoptosis in peripheral blood lymphocytes of rats. Hum Exp Toxicol 36:1158-1168.

Oruc S, Gönül Y, Tunay K, Oruc OA, Bozkurt MF, Karavelioğlu E, Bağcıoğlu E, Coşkun KS, Celik S (2016) The antioxidant and antiapoptotic effects of crocin pretreatment on global cerebral ischemia reperfusion injury induced by four vessels occlusion in rats. Life Sci 154:79-86.

Rahbardar MG, Hosseinzadeh H (2020a) Effects of rosmarinic acid on nervous system disorders: an updated review. Naunyn Schmiedebergs Arch Pharmacol 393:1779-1795.

Rahbardar MG, Hosseinzadeh H (2020b) Therapeutic effects of rosemary (Rosmarinus officinalis L.) and its active constituents on nervous system disorders. Iran J Basic Med Sci 23:1100-1112.

Rastgoo M, Hosseinzadeh H, Alavizadeh H, Abbasi A, Ayati Z, Jaafari MR (2013) Antitumor activity of PEGylated nanoliposomes containing crocin in mice bearing C26 colon carcinoma. Planta Med 79:447451.

Razavi BM, Hosseini A, Hosseinzadeh H (2021) Antidepressant activity of Crocus sativus L. and its main constituents: A review. The Neuroscience of Depression: Academic Press. p 493-502.

Razavi BM, Hosseinzadeh H, Abnous K, Khoei A, Imenshahidi M (2016) Protective effect of crocin against apoptosis induced by subchronic exposure of the rat vascular system to diazinon. Toxicol Ind Health 32:1237-1245.

Razavi BM, Hosseinzadeh H, Movassaghi AR, Imenshahidi M, Abnous K (2013) Protective effect of crocin on diazinon induced cardiotoxicity in rats in subchronic exposure. Chem Biol Interact 203:547-555.

Salama RM, Abdel-Latif GA, Abbas SS, Hekmat M, Schaalan MF (2020) Neuroprotective effect of crocin against rotenone-induced Parkinson's disease in rats: Interplay between PI3K/Akt/mTOR signaling pathway and enhanced expression of miRNA-7 and miRNA-221. Neuropharmacology 164:107900.

Sandhu KS, Rana AC (2013) Evaluation of anti parkinson's activity of Nigella sativa (kalonji) seeds in chlorpromazine induced experimental animal model. Int J Pharm Pharm Sci 22:23.

Schmitt I, Kaut O, Khazneh H, deBoni L, Ahmad A, Berg D, Klein C, Fröhlich H, Wüllner U (2015) L-dopa increases a-synuclein DNA methylation in Parkinson's disease patients in vivo and in vitro. Mov Disord 30:1794-1801.

Shahidani S, Rajaei Z, Alaei H (2019) Pretreatment with crocin along with treadmill exercise ameliorates motor and memory deficits in hemiparkinsonian rats by anti-inflammatory and antioxidant mechanisms. Metab Brain Dis 34:459-468.

Shaterzadeh-Yazdi H, Samarghandian S, Farkhondeh T (2018) Effects of crocins in the management of neurodegenerative pathologies: a review. Neurophysiology 50:302-308. 
Sherer TB, Kim J-H, Betarbet R, Greenamyre JT (2003) Subcutaneous rotenone exposure causes highly selective dopaminergic degeneration and a-synuclein aggregation. Exp Neurol 179:9-16.

Shieh P, Jan C-R, Liang W-Z (2019) The protective effects of the antioxidant N-acetylcysteine (NAC) against oxidative stress-associated apoptosis evoked by the organophosphorus insecticide malathion in normal human astrocytes. Toxicology 417:1-14.

Singh R, Letai A, Sarosiek K (2019) Regulation of apoptosis in health and disease: the balancing act of BCL-2 family proteins. Nat Rev Mol Cell Biol 20:175-193.

Srivastav S, Fatima M, Mondal AC (2017) Important medicinal herbs in Parkinson's disease pharmacotherapy. Biomed Pharmacother 92:856-863.

Tang J, Lu L, Wang Q, Liu H, Xue W, Zhou T, Xu L, Wang K, Wu D, Wei F (2020) Crocin reverses depressionlike behavior in Parkinson disease mice via VTA-mPFC pathway. Mol Neurobiol 57:3158-3170.

Thakur P, Nehru B (2014) Modulatory effects of sodium salicylate on the factors affecting protein aggregation during rotenone induced Parkinson's disease pathology. Neurochem Int 75:1-10.

Thanvi B, Lo T (2004) Long term motor complications of levodopa: clinical features, mechanisms, and management strategies. Postgrad Med J 80:452-458.

Toth C, Brown MS, Furtado S, Suchowersky O, Zochodne D (2008) Neuropathy as a potential complication of levodopa use in Parkinson's disease. Mov Disord 23:1850-1859.

Uversky VN, Li J, Fink AL (2001) Pesticides directly accelerate the rate of a-synuclein fibril formation: a possible factor in Parkinson's disease. FEBS Lett 500:105-108.

Varol S, Başarslan S, Fırat U, Alp H, Uzar E, Arıkanoğlu A, Evliyaoğlu O, Acar A, Yücel Y, Kıbrıslı E (2015) Detection of borderline dosage of malathion intoxication in a rat's brain. Eur Rev Med Pharmacol Sci 19:2318-2323.

Venkatesan R, Park YU, Ji E, Yeo E-J, Kim SY (2017) Malathion increases apoptotic cell death by inducing lysosomal membrane permeabilization in N2a neuroblastoma cells: a model for neurodegeneration in Alzheimer's disease. Cell Death Discov 3:1-10.

Warner TT, Schapira AH (2003) Genetic and environmental factors in the cause of Parkinson's disease. Ann Neurol Society 53:S16-S25.

Wu B, Song B, Yang H, Huang B, Chi B, Guo Y, Liu H (2013) Central nervous system damage due to acute paraquat poisoning: an experimental study with rat model. Neurotoxicology 35:62-70.

Yu D, Zhang P, Li J, Liu T, Zhang Y, Wang Q, Zhang J, Lu X, Fan X (2020) Neuroprotective effects of Ginkgo biloba dropping pills in Parkinson's disease. J Pharm Anal 11:220-231. 
Zeinali M, Zirak MR, Rezaee SA, Karimi G, Hosseinzadeh H (2019) Immunoregulatory and antiinflammatory properties of Crocus sativus (Saffron) and its main active constituents: A review. Iran J Basic Med Sci 22:334.

Zucca FA, Segura-Aguilar J, Ferrari E, Muñoz P, Paris I, Sulzer D, Sarna T, Casella L, Zecca L (2017) Interactions of iron, dopamine and neuromelanin pathways in brain aging and Parkinson's disease. Prog Neurobiol 155:96-119.

\section{Figures}



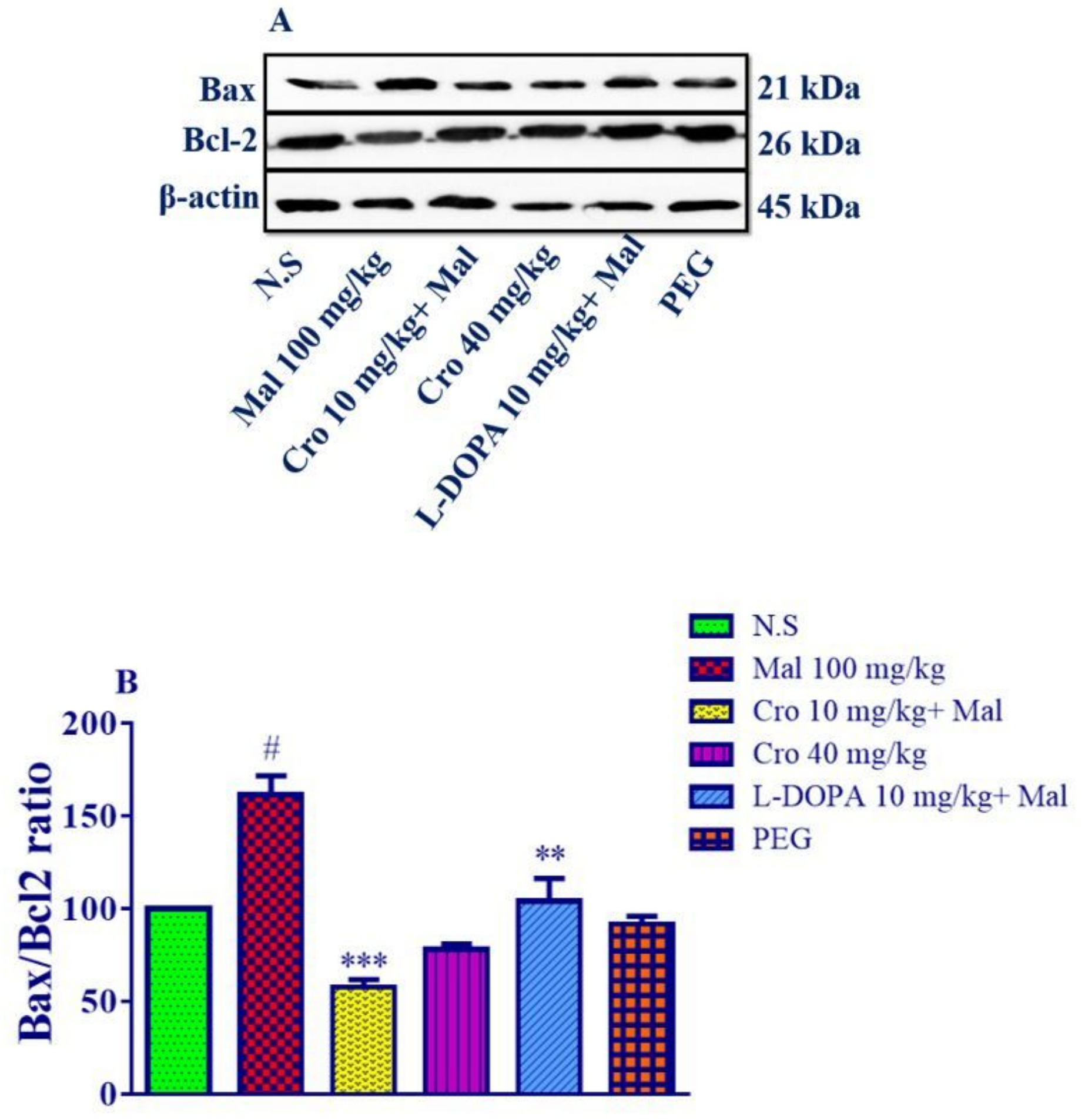

Figure 1

The effect of malathion and crocin on the amount of Bax and Bcl-2 proteins in rat striatum after 4 weeks by Western blotting. A: Bax, Bcl-2, and $\beta$-actin (internal control) specific bands. Equal amounts of protein samples $(100 \mu \mathrm{g})$ obtained from striatum tissue homogeneity were loaded in each row. These bands represent 4 independent experiments. B: Densitometric results of Bax/Bcl-2 ratio. Results were expressed as mean \pm SEM. Tukey-Kramer statistical test was used to evaluate the level of statistical differences 


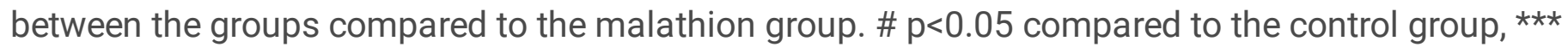
$p<0.001$, and ${ }^{* \star} p<0.01$ compared to the malathion group. Mal: Malathion, Cro: Crocin: N.S: Normal Saline, L-DOPA: Levodopa, PEG: Polyethylene glycol
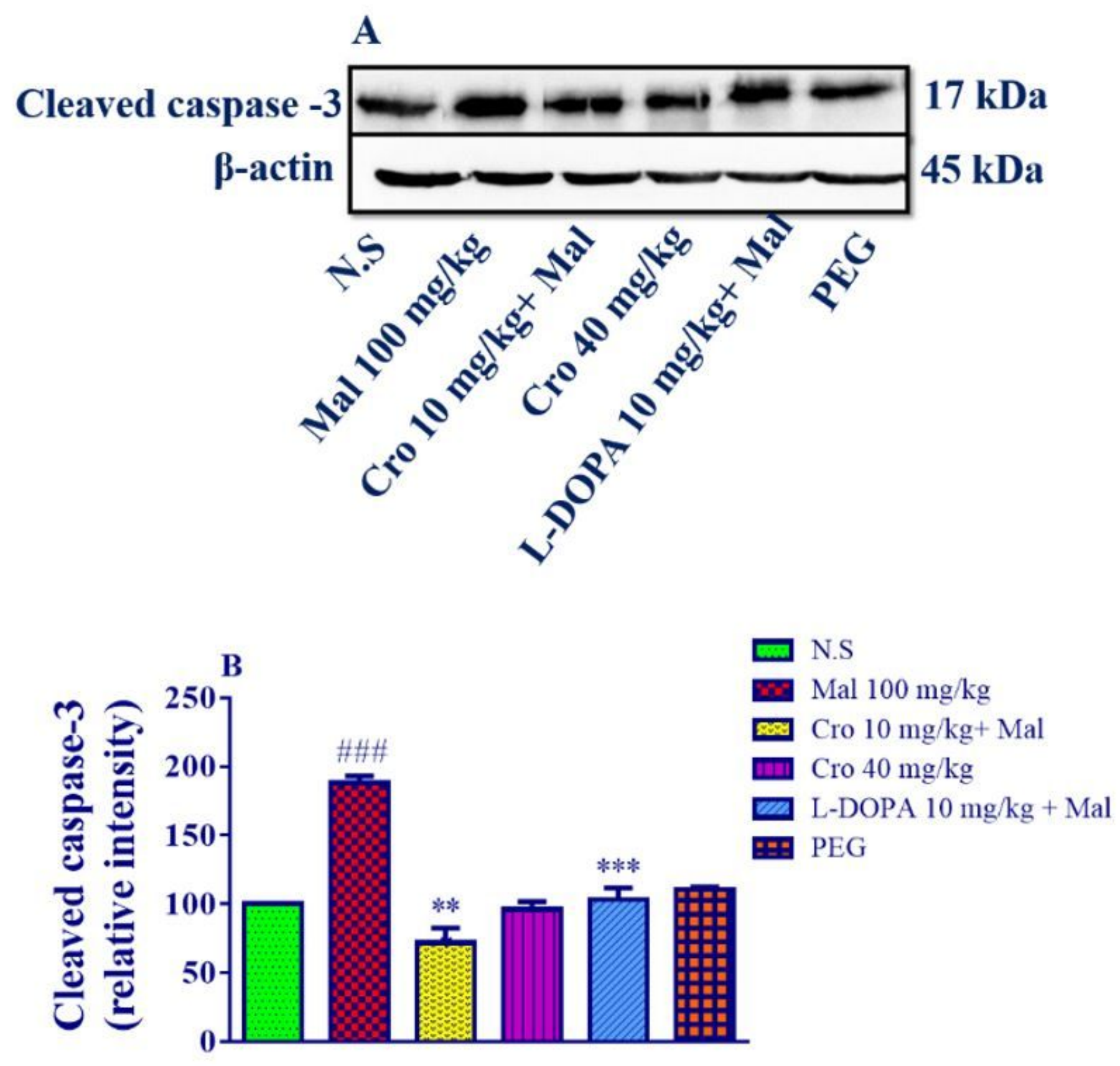

Figure 2

The effect of malathion and crocin on cleaved caspase-3 protein in rat striatum after 4 weeks by Western blotting. A: Cleaved caspase- 3 and $\beta$-actin (internal control) specific bands. Equal amounts of protein samples $(100 \mu \mathrm{g})$ obtained from striatum tissue homogeneity were loaded in each row. These bands represent 4 independent experiments. B: Densitometric results of cleaved caspase-3. Results were expressed as mean \pm SEM. Tukey-Kramer statistical test was used to evaluate the level of statistical 
differences between the groups compared to the malathion group. \#\#\# $\mathrm{p}<0.001$ compared to the control group, ${ }^{\star \star \star} p<0.001$ compared to the malathion group. Mal: Malathion, Cro: Crocin: N.S: Normal Saline, LDOPA: Levodopa, PEG: Polyethylene glycol
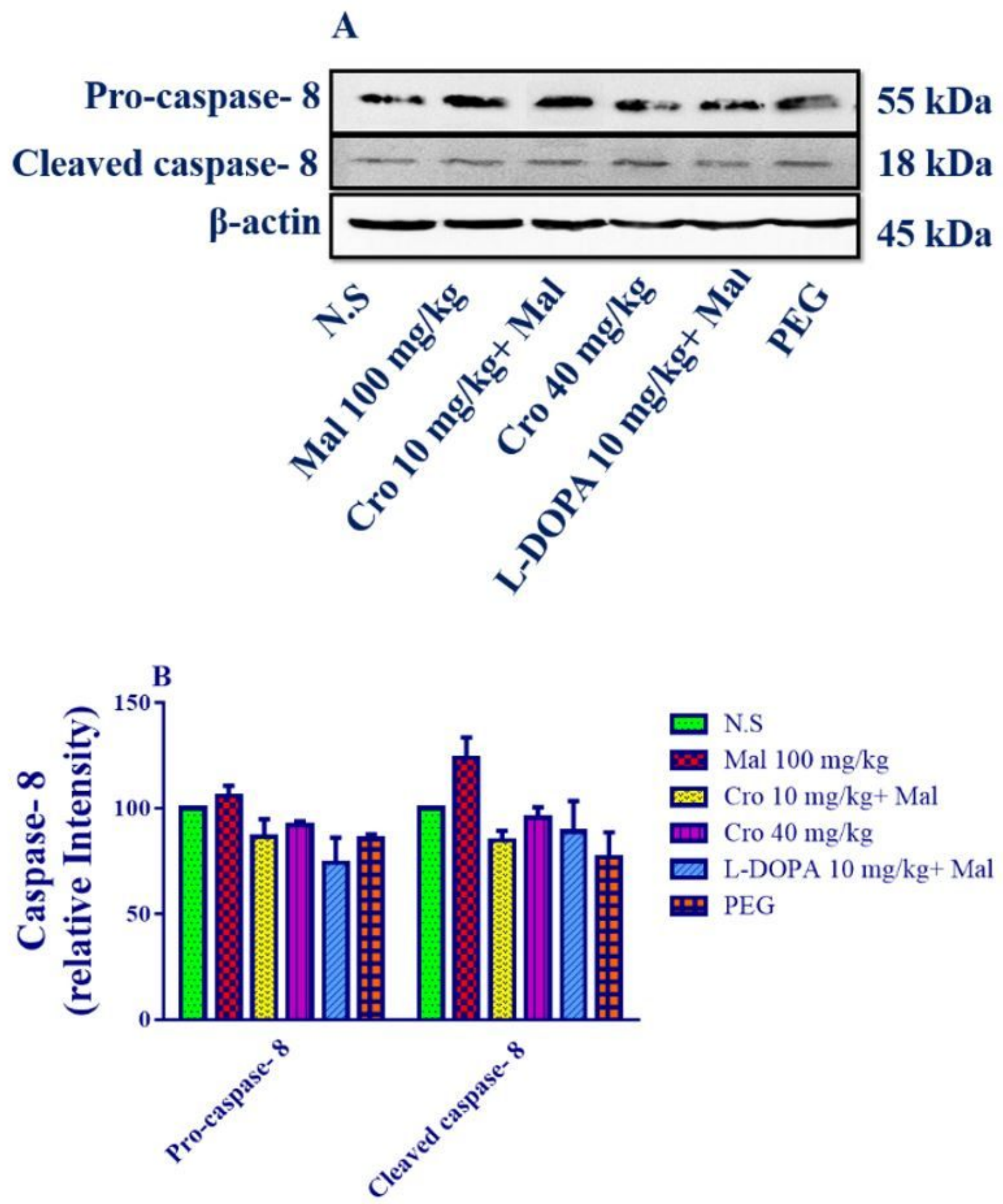

Figure 3

The effect of malathion and crocin on cleaved and pro caspase- 8 proteins in rat striatum after 4 weeks by Western blotting. A: Cleaved caspase-8, Pro caspase-8, and $\beta$-actin (internal control) specific bands. Equal 
amounts of protein samples $(100 \mu \mathrm{g})$ obtained from striatum tissue homogeneity were loaded in each row. These bands represent 4 independent experiments. B: Densitometric results of cleaved caspase-8, Pro caspase-8. Results were expressed as mean \pm SEM. Tukey-Kramer statistical test was used to evaluate the level of statistical differences between the groups compared to the malathion group. Mal: Malathion, Cro: Crocin, N.S: Normal Saline, L-DOPA: Levodopa, PEG: Polyethylene glycol
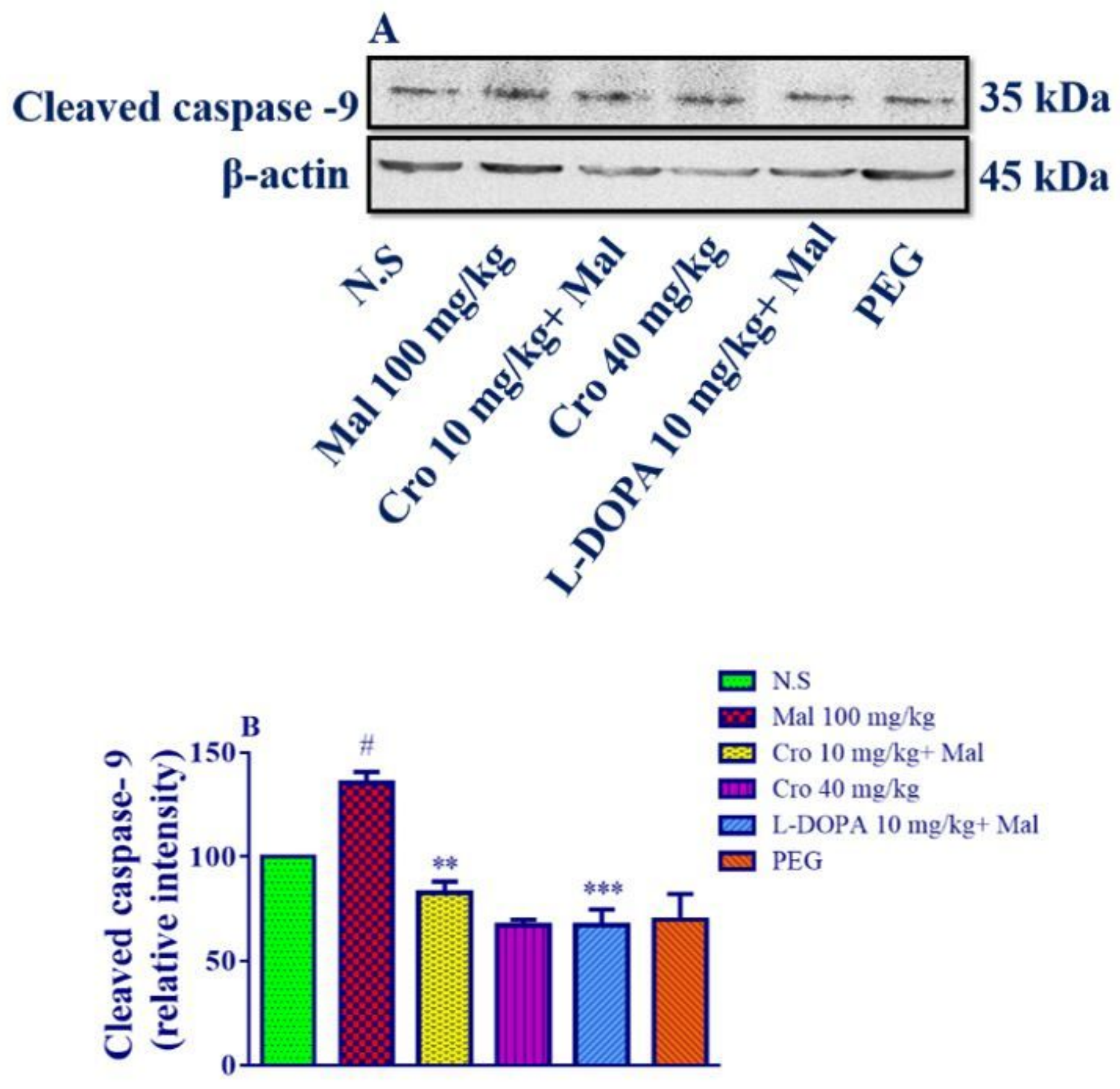

Figure 4

The effect of malathion and crocin on cleaved caspase-9 protein in rat striatum after 4 weeks by Western blotting. A: Cleaved caspase 9 and $\beta$-actin (internal control) specific bands. Equal amounts of protein 
samples $(100 \mu \mathrm{g})$ obtained from striatum tissue homogeneity were loaded in each row. These bands represent 4 independent experiments. B: Densitometric results of cleaved caspase-9. Results were expressed as mean \pm SEM. Tukey-Kramer statistical test was used to evaluate the level of statistical differences between the groups compared to the malathion group. \# $p<0.05$ compared to the control group, ${ }^{* \star} p<0.001$ and ${ }^{* *} p<0.01$ compared to the malathion group. Mal: Malathion, Cro: Crocin: N.S: Normal Saline, L-DOPA: Levodopa, PEG: Polyethylene glycol
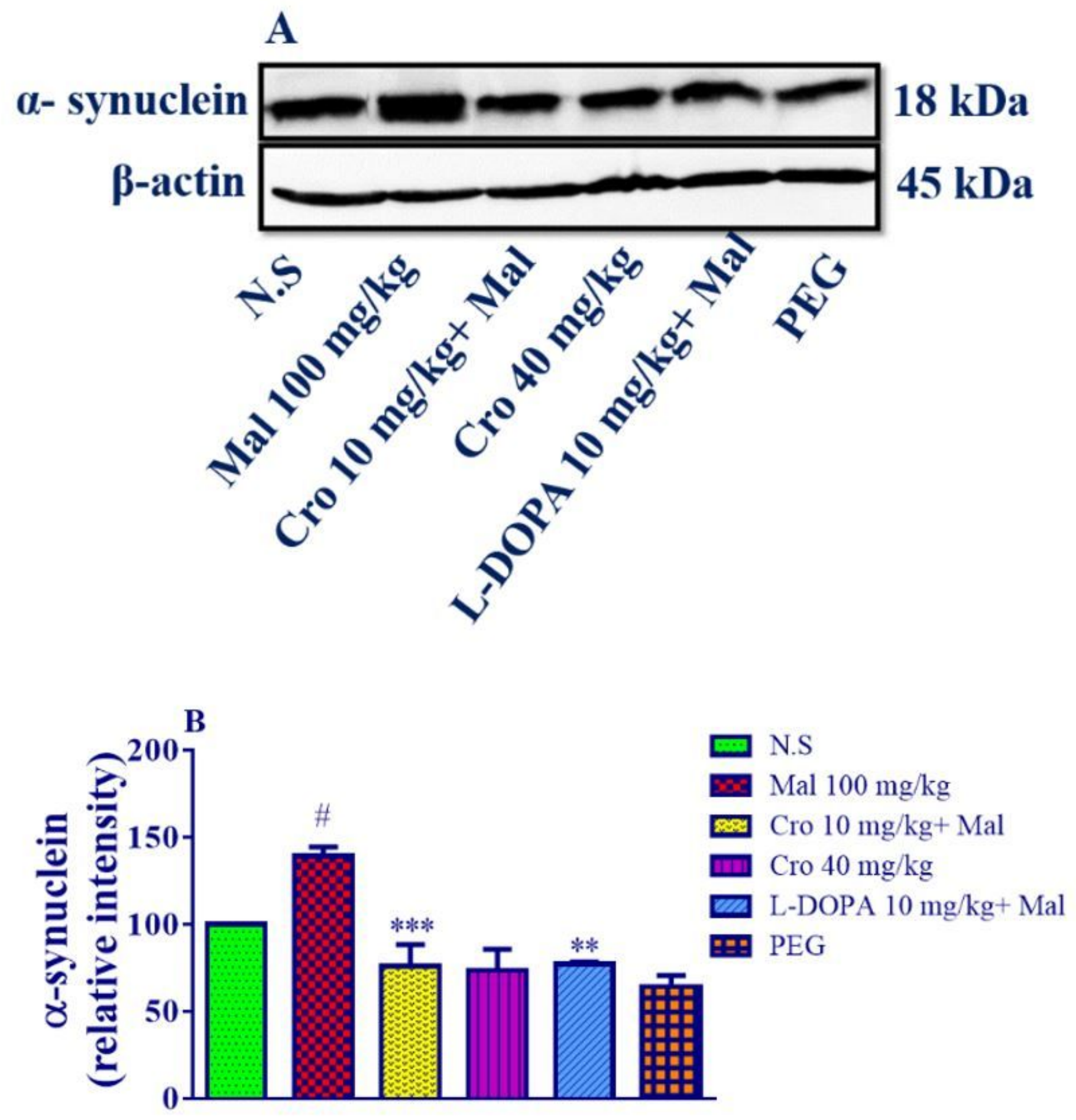

Figure 5 
The effect of malathion and crocin on a-synuclein protein in rat striatum after 4 weeks by Western blotting. A: Specific a-synuclein and $\beta$-actin (internal control) specific bands. Equal amounts of protein samples $(100 \mu \mathrm{g})$ obtained from striatum tissue homogeneity were loaded in each row. These bands represent 4 independent experiments. B: a-synuclein densitometric results. Results were expressed as mean \pm SEM. Tukey-Kramer statistical test was used to evaluate the level of statistical differences between the groups compared to the malathion group. \# $p<0.05$ compared to the control group, ${ }^{* * *} p<0.001$ and ${ }^{* *} p<0.01$ compared to the malathion group. Mal: Malathion, Cro: Crocin, N.S: Normal Saline, L-DOPA: Levodopa, PEG: Polyethylene glycol

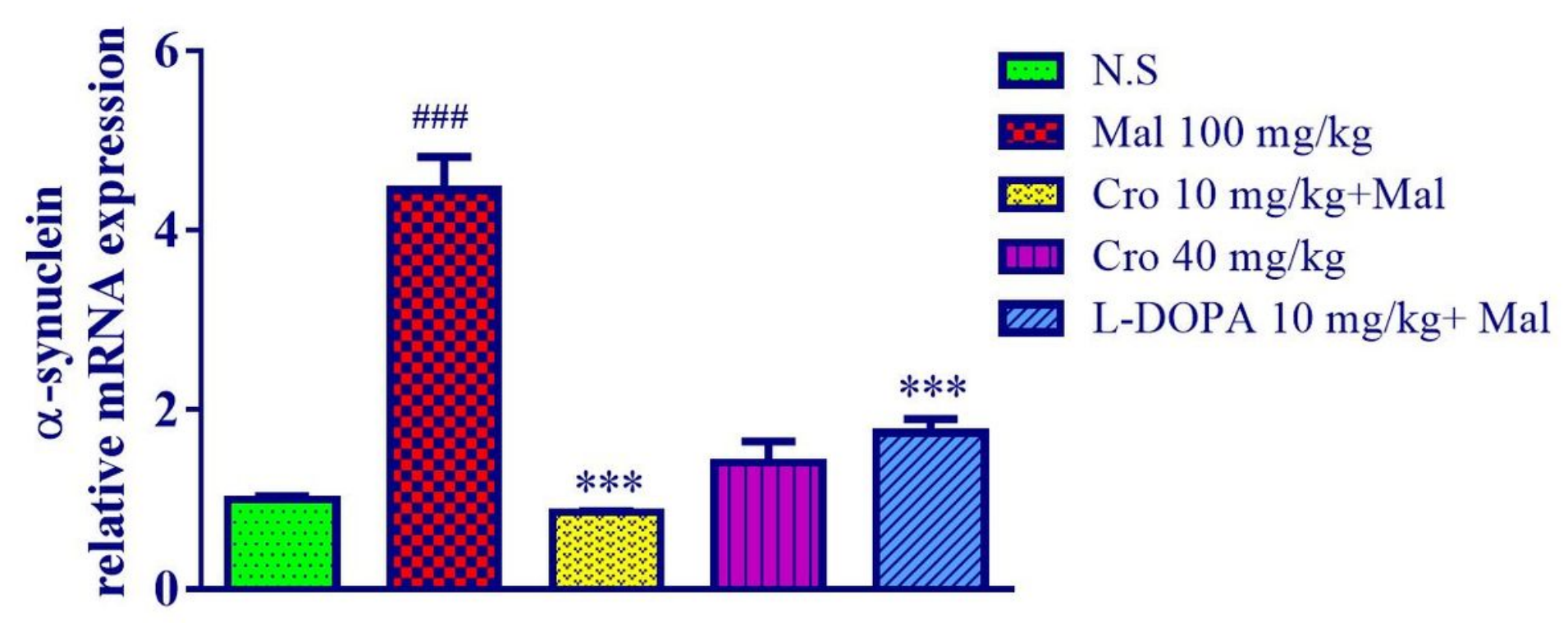

Figure 6

The effect of malathion and crocin on the a-synuclein mRNA level in rat striatum after 4 weeks by RTqPCR. Expression was normalized by $\beta$-actin gene expression. mRNA values were expressed relative to the control group cells and based on obtained mean \pm SEM from 4 independent experiments. TukeyKramer statistical test was used to examine the level of statistical differences between the groups compared to the malathion group. \#\#\# $p<0.001$ compared to control group, ${ }^{\star \star *} p<0.001$ compared to the malathion group, Mal: Malathion, Cro: Crocin, L-DOPA: Levodopa, PEG: Polyethylene glycol 